\title{
Cohesion and Competition of Europe: Innovation Policy from the Perspective of Networks and Entropy
}

\author{
Umut Yılmaz Çetinkaya a \\ Expert, uycetinkaya@gmail.com. \\ Erkan Erdil ${ }^{b}$ \\ Professor, erdil@metu.edu.tr. \\ a YNR Consulting, Ugur Mumcu Cad. 55, 306700 G.O.P., Cankaya, Ankara, Turkey. \\ b Department of Economics, Middle East Technical University (Universiteler Mahallesi), \\ 1 Dumlupinar Bulvari, 06800 Cankaya-Ankara, Turkey.
}

\begin{abstract}
$\mathrm{T}$ his study analyzes the innovation performance of the European Union in the context of the European Research Area (ERA). Literature related to the Systems of Innovation, network studies, Framework Programs and the European Research Area will be used to establish a theoretical framework for policy analysis. It forms a database from three different resources to establish a European Research and Innovation Network, which appears as a result of policy and program implementation at the European level. The evaluation of the European Union's
\end{abstract}

Abstract

Keywords: systems of innovation; networks; Innovation Union; entropy; STI Policy.

DOI: 10.17323/1995-459X.2016.4.7.24. innovation performance is discussed for developing policy recommendations, which are derived from theoretical arguments as well as analytical studies, based on network analysis and the notion of entropy. The implementation of a relatively simple rule by the European Commission, in addition to policies focusing on the development of countries' diversity and absorptive capacity, which are structural holes, may make an important contribution to improving cohesion and competition within the European Research Area, as well innovation in the European Union.
Citation: Çetinkaya U.Y., Erdil E. (2016) Cohesion and Competition of Europe: Innovation Policy from the Perspective of Networks and Entropy. Foresight and STI Governance, vol. 10, no 4, pp. 7-24. DOI: 10.17323/1995-459X.2016.4.7.24. 
$\mathrm{W}$ ith regards to innovation performance, Europe is falling behind its main competitors, the fact that its innovation performance is not at the desired level is a topic that has been extensively discussed and studied in the relevant literature [European Commission, 1995; 1997; Caracostas, Muldur, 1998; Fagerberg et al., 1999; Malerba, 2004; Asheim et al., 2011; Camagni, Capello, 2013; etc.]. Targets set to increase the innovation performance of Europe or improve its competitiveness are expressed more often than not in the implementation of programs, such as framework programs (FP). The goal of these programs is to increase the potential and opportunities of EU members deemed innovative and competitive, as well as rapidly develop these characteristics in less innovative and competitive members. Many academic studies, some of which are mentioned above, were carried out on the measures implemented to fulfill this task, and it seems that there are many more studies to come. Accordingly, rather than repetitive research, studies on specific topics with an interdisciplinary approach in the area could make important contributions to increasing innovation in Europe.

This study focuses innovation performance of the European Union (EU). In order to evaluate and provide policy recommendations for improving the EU's innovation performance, various well-founded academic arguments and EU projects are evaluated. The basic academic framework of this study is based on the Systems of Innovation (SIs) approach. Not only innovation indicators, but also the network, which the authors designate as the European Research and Innovation Network in this study, is obtained from the practical projects implemented by the European Commission (EC). The database for innovative performance and network analysis is constructed using the data from the Innovation Union Scoreboard (IUS), Regional Innovation Scoreboard (RIS), and CORDIS. The study of innovation and network relations is also supported by the European Research Area (ERA), another EC major policy. The results of this analysis became the inputs for policy recommendations, which are based on an academic discussion of the systems of innovation (SI) for increasing innovation performance of the European Union.

The following two sections will determine the paper's theoretical framework. We will discuss the relationships between SIs, networks and the Innovation Union. Then we will introduce how the concept of entropy, specifically Boltzmann's and Prigogine's views, will be used in this article. After that, data and methodological foundation for the establishing and analyzing the European Research and Innovation Network will be explained. In short, the followings will be analyzed: the network containing the nodes formed by countries and regions (NUTS-2); the relationship between the innovation performance of countries and regions with a network structure will be discussed; the ERA will be examined in order to observe whether it has been on the intended track or not; network analysis and entropy calculations will be used to analyze the innovation performance of the EU; finally policy recommendations to increase innovation performance of the European Union will be presented.

The aforementioned discussions will yield two policy recommendations and tools to improve the innovation performance of the European Union. A key recommendation is that a simple rule be established, stating that requirements be set by the European Commission in the project application process for the inclusion of a node with a low eigenvector value in the project consortium may help increase the cohesion and innovation performance of Europe. In terms of the EU's competitiveness, in light of the ability of important gatekeepers to connect with global networks but the system's low absorptive capacity in terms of benefiting from those competitors, it will be proposed that policymakers of the EU focus more on the development of diversity and absorptive capacity of nodes, structural holes, in order to benefit more from the European Research and Innovation Network in increasing the innovation performance of the EU.

\section{Systems of Innovation, Networks and the Innovation Union}

Scholars in the field of innovation studies focus on the impact of network structures on the production of information and knowledge, as well as their transformation into new products and services and processes [Powell, Grodal, 2005]. Andersen [Andersen, 1996; 1997] focuses on graph theory and simulation models within the SIs framework. Some researchers examined the geographical distribution of the innovation network and the relationship of geography within the network [Becattini, 1990; Camagni, 1991; Cooke, 1996; Marshall, 1961; Piore, Sabel, 1986; Storper, 1997; Asheim, Gertler, 2005]; while others studied the structural characteristics of the network [Das, Teng, 2002]; or the governance of the network structure [Pietrobelli, Rabellotti, 2009; Gereffi et al., 2005; Sturgeon et al., 2008]; and others were concerned with cognitive distance between the participants in a network [Gereffi et al., 2005]; and the strength of the ties between said participants [Granovetter, 1973], the production and transfer of knowledge and information and their impact on the creation and development of innovations [Nooteboom, 2004]. Many authors analyzed the impact of inter-organizational networks on innovation [DeBresson, Amesse, 1991; Freeman, 1991; Hagedoorn, 1990, 1993; Nooteboom, 2004; Powell et al., 1996; Soh, Roberts, 2003].

As evident from the abundance of the studies in the field over the course of the last decade, the role of networks in science, technology and innovation (STI) policies have been increasingly discussed. The key idea behind this discussion is the focus on interactions among various actors as the most important factor for developments in STI. In other words, instead of focusing on a single actor and its behaviors, policymakers have started to focus on the importance of cooperation, collaboration and communication among numerous actors. In fact, the expectations of policymakers concerning network analysis were already articulated in notable works [Freeman, 1991; Lundvall, 1992; Metcalfe, 1995; Foray, Lundvall, 1996], which are considered the building blocks for the SIs approach. 
Innovation processes involve the generation and application of knowledge, where the success or failure of any SIs depends mainly on how the knowledge of actors is integrated via networks [Foray, 2006] and on the structure of the SIs. With these networks, actors not only achieve dispersed specific and diversified knowledge, but also obtain more opportunities to increase their internal knowledge [Kogut, Zander, 1992; Powell et al., 1996]. The reason for this, Allen [Allen, 2001] said is that diversity among actors in a system increases the effectiveness of the system. It is diversity that enables actors in SIs to evaluate and respond to the demands not only of the market, but also the system itself. If new knowledge is introduced into the system, regardless of whether it is produced within the system or not, the actors of the system's 'cognitive distance' [Nooteboom, 1992, 2005] start to become similar and the system encounters inertia or lock-in.

The impact and structure of networks on the production and diffusion, dissemination and distribution of knowledge resulting from actors and their interactions, began to gain recognition in the literature in the 2000s [Malerba et al., 2007]. For instance, Latora \& Marchiori [Latora, Marchiori, 2004] state that "the network structure can be as important as the nonlinear interactions between elements, and... structural properties of the network can be of fundamental importance for understanding the dynamics of the system". Networks have an important role to play in maximizing the advantages obtained from the creation and diversification of knowledge and the intensification of cooperation in the SIs approach.

Regarding the negative factors, most intervention policies of governing bodies are not developed within the framework of the network approach [Hyötyläinen, 2000]. At the same time, research has shown little interest in policy questions related with networks, though these policies have potential to be important components in the development of appropriate policies. Among others, two reasons may be stated as to why the relationship between network analysis and policy are overlooked by researchers. First is the lack of appropriate data and the second is, as stated by Carlsson [Carlsson, 2000] and Flap et al. [Flap et al., 1998]: the network approach is subject to the explanatory power.

On a positive note, network analysis has started to become an important component for policy development and implementation as an increasing number of actors, blurred boundaries and roles among actors, dispersed (especially tacit) knowledge, deepening interdependencies, etc., make network analysis techniques a good option for a policy development and implementation. That is, networks "are an important component of national systems of innovation. An important function of science and technology policy is to strengthen existing innovation-related networks and to help build networks in areas where they are lacking" [OECD, 1992]. Therefore, policy analysis "is finding out what governments do, why they do it, and what differences it makes" [Dye, 2012]; network analysis enables policymakers to study the structure and corresponding configurations. For instance, Peterson [Peterson, 2003] states that "policy network analysis is never more powerful as an analytical tool than when it is deployed at the EU level' and 'few ... would deny that governance by networks is an essential feature of the EU'. In this sense, the reduction of the failures stemming from the network, or use of a network to increase competitiveness and innovation performance as much as possible, necessitates the development and implementation of appropriate policies.

In short, following the termination of the first framework program (FP1) in 1987, the second (19871991) and third (1990-1994) framework programs (FPs) were implemented, demonstrating the characteristics of a technology push model. At around the same time, the systems of innovation view started to pervade policy advisory circles [Soete, Arundel, 1993]. Indeed, this approach was reflected in FP4 (1994-1998), where particular support was provided for such areas as the diffusion of technology, the integration of SMEs, training, and mobility. Employing a user-oriented approach, FP5 (1998-2002) was shaped specifically for solving societal problems and socioeconomic challenges, as well as increasing research opportunities and the potential for cutting-edge technologies. In the last two decades, the role of innovation in the context of European development has grown in importance [European Commission, 2000, 2006, etc.]. FP6 (2002-2006) may be regarded as an important break with the previous FPs. It focused on science and technological advancements and, a technology push in a similar way to FP2 and FP3. However FP6 introduced new instruments (integrated projects and networks of excellence) and encouraged a rise in the number of partners in the projects to obtain critical mass. Moreover, it also endeavored to facilitate the ERA in overcoming underinvestment in R\&D, fragmentation of research, and coordination problems at different levels.

FP7 was aimed at strengthening the scientific and technological base of European industry as well as at encouraging its international competitiveness, while promoting research that supports EU policies. Therefore, starting from FP6, and particularly in FP7, not only the number of participants in FP projects' network increased; but also, especially, after the articulation of the European Research Area (ERA) in 2000, framework programs became one of the major tools for European research and innovation policymaking. By leveraging sufficient additional funding for research, development and innovation, it is expected that FP8 (Horizon 2020) will tangibly contribute to building and developing an economy based on knowledge and innovation across the entire EU. In this way, it will not only support the Europe 2020 strategy and other policies to be implemented, but it will also contribute to the targets of the ERA, which were enumerated as follows: "[t]he Innovation Union must involve all regions. The financial crisis is having a disproportionate impact on some less performing regions and hence risks undermining recent convergence. Europe must avoid an 'innovation divide' between the strongest innovating regions [countries] and the others" [European Commission, 2010a]. 
When the explanations up to this point are analyzed at the country level, it is not difficult to say that although several rankings place EU member states such as Sweden, Finland, Germany, Denmark, and UK among the world leaders in terms of innovation performance, the rest of the EU member states remain mid-range, and the aggregate performance of the EU27 lags behind that of US and Japan, despite their significant prevalence over BRICS countries. In addition, China and India are quickly catching up with the former, displaying a particularly rapid rate of relative improvement; where, if China maintains its rate of improvement over the last five years, the performance gap with the EU27 will diminish in the short term [Archibugi et al., 2009]. Moreover, other Asian countries, such as South Korea and Singapore, which recently came to be considered the new innovation hot-spots, are also on their way forward. The Innovation Union Scoreboard 2013 depicts South Korea as being beside the US and Japan and having a performance lead over the EU27.

Therefore, Europe began to lose its relative headway in the production of knowledge, not necessarily because Europe does less, but rather because the others do more. A distribution pattern similar to these countries can also be observed among regions (as shown in RIS 2012) for which, due to intensified global competition, it is necessary to implement 'smart specialization' approaches to strengthen the existing 'hot spots' of innovation, which would give regions the edge needed to determine niche development strategies that would allow them to meet local needs and survive this evolutionary phase of knowledge-based societies [Foray, van Ark, 2007; European Commission, 2010b]. By and large, Europe's underachievement, as demonstrated in the RIS 2012 and IUS 2013 data, indicates not only the low performance in growth and jobs, but also the impediments hindering the completion of the ERA.

\section{Entropy}

As stated by Boltzmann [Boltzmann, 1974], the macrostate of a gas is determined by temperature, inner energy, pressure and volume, while the microstate of a system is portrayed by momentum $(p x, p y, p z)$ and spatial coordinates $(x, y, z)$ of each point comprising the macrostate. There are many microstates, and entropy measures the number of macrostates (or conditions) that can be fulfilled. Put differently, when entropy is 0 (zero), there is only one microstate, implying full predictability, which means there is no possibility of another microstate. On the other hand, when the entropy is higher, there are more possibilities for microstates, bringing a lower degree of predictability. From the point of view of SIs, this situation can be characterized as the existence of more possibilities for microstates, indicating higher entropy, which means that entities are capable of innovating. This can also be depicted in Boltzmann's entropy formula, a probability equation relating the entropy $S$ of an ideal gas to the quantity $W$, which is the number of microstates corresponding to a given macrostate. Provided below, Boltzmann's formula shows the relationship between entropy and the number of ways atoms or molecules of a thermodynamic system can be arranged:

$S=k \log W$ or $S=-\sum_{i} w_{i} \ln \left(w_{i}\right)$

For instance, we assume that there are events $i(i=1,2,3, \ldots, n)$ occurring with probabilities $w_{i}, \sum_{i} w_{i}=1$ and $0 \leq w_{i} \leq 1$.

If an event is realized with absolute certainty $w_{i}=1$, we obtain $S=0 \quad(\ln 1=0)$. Accordingly, probabilities of $\mathrm{w}_{\mathrm{i}}$ can signify the capability of genes to change or adapt a system; or the emergence of an innovation within a system. Therefore, entropy is lower when probability is less distributed; or entropy is higher when probability is distributed equally. As a result, the lowest entropy means either maximum order (all microstates in one macrostate) or maximum certainty of a single outcome. The highest entropy (equal distributions of microstates and all macrostates) means either maximum uncertainty regarding the outcome or the greatest opportunity for innovation.

In the concept of entropy, it is argued that we cannot see any exchanges in a closed system through the boundaries of the system due to the lack of gradients, and consequently, the system reaches equilibrium (maximum entropy), a process which is irreversible [Prigogine, Stengers, 1984]. That is, the ability of a system to perform work is restricted; as such, the entropy of an isolated system never decreases due to the second law of thermodynamics, resulting in a lock-in or entropic death [Saviotti, 1988]. On the other hand, Prigogine explained that sum of entropy is made up of imported entropy and entropy produced in open systems. In 'dissipative structures', developed by Prigogine [Prigogine, 1976] and other members of the Brussels school as open systems, entropy disappears from the system, which increases the organization of the system at the expense of increased disorder in its environment. Therefore, dissipative structures, demonstrating the ability to self-organize by exporting entropy via fluctuations and working under conditions far from equilibrium, denote a system which is highly organized but always in transition and dependent on the flux of inputs.

\section{Data and Methodology}

Obviously, the precision of any analytical study is determined by the accuracy of the presented data. For this purpose, data from Innovation Union Scoreboard (IUS), Regional Innovation Scoreboard (RIS), and CORDIS are prepared for analysis. The database constructed using these three resources permitted an analysis to be used for the development of policy recommendations in the following sections. Furthermore, the two main approaches to entropy, by Boltzmann and Prigogine, are used for analyzing the relationships between network structure and innovation performance. 


\section{Data}

CORDIS "is the European Commission's primary public repository and portal for disseminating information on all EU-funded research projects and their results in the broadest sense"1. IUS and RIS databases will be used to set up a relationship between the network established by CORDIS participants and the notion of innovation. The IUS provides the innovative values for many Europe countries, as well as relative innovative values for some important partner countries outside the EU. The RIS, on the other hand, provides the innovative values of many European regions (NUTS-2). Combining these three resources, a database was created for the article, allowing us to focus on and develop policy recommendations for increasing the innovation performance of the European Union from the perspective of network analysis. Inconsistencies in the raw CORDIS data obtained from the European Commission were removed from the database in order to use it in network analysis. As such, not all information concerning the projects and participants could be acquired from the raw database; some projects lacked budget information, while the names of the participants, or project timeframes were missing in others, and so on. For example, while the raw database contained 40,097 participants and 12,386 projects in FP4, a cross-check of the start and end dates of projects in FP4 yielded 41,988 participants and 12,815 projects in FP4. When data was further specified based on two criteria (program name and timeframe), 36,320 participants and 11,108 projects remained as the inputs for the FP4 network.

\section{Method}

A network, modeled on three stages, called the European Research and Innovation Network, was formed using the database established for this article in order to analyze and discuss the innovation performance of Europe and the ERA. The first stage, which will be called an 'open network', is modeled at the country level, and includes all nodes, which are participants of the FPs (both European and non-European). The second stage is a network, called a 'closed network' comprised of the countries, which are mentioned in the IUS 2013 document as nodes. Finally, a network called the 'regional network' is formed for NUTS-2 level regions.

After modeling the European Research and Innovation Network at three stages, standard measurement techniques were applied to inspect network characteristics such as path length, clustering coefficients, and so on. They will then be employed to explore this network in terms of innovation performance and in order to analyze the ERA in terms of the cohesion and competitiveness of Europe. For an exploration of the relationships between characteristics of network and innovativeness of countries and regions (NUTS-2), which are also nodes in the European Research and Innovation Network, innovation performance of countries and regions obtained from IUS 2013 and RIS 2012 respectively, are correlated with network values of the past six years.

Finally, the study uses from the notion of entropy in analyzing the innovation performance of Europe with an approach that greatly diverges from the general usage and interpretation of the concept. Many studies focus on network entropy from the point of distribution of links between nodes. For instance, Mowshowitz [Mowshowitz, 1968] developed an approach based on graph invariants such as vertex degrees, distances, etc., and on an equivalence criterion for information-theoretic measures. Nishikawa et al. [Nishikawa et al., 2003] quantified the heterogeneity of complex networks using the standard deviation of degree. Solé \& Valverde [Solé, Valverde, 2004] proposed using entropy of remaining degree distribution for heterogeneity, which is also discussed by Bar-Yam [Bar-Yam, 2003]. Wang et al. [Wang et al., 2006] suggested using entropy of degree distribution to measure the heterogeneity of complex networks. Wu et al. [Wu et al., 2010] proposed that entropy of degree sequence be used a measure of the heterogeneity of complex networks.

Basically, if a network is comprised of telephones and lines, or web pages and links, where there are stable links among nodes, it may be useful to consider the role of links in terms of entropy analyses. As observed in these network examples, if there are concrete nodes and links among constituents of networks, it is important to make probability calculations in line with Shannon's formula [Shannon, 1948] to find out the entropy of a network. On the other hand, when we talk about innovation, we cannot see concrete nodes and links among the components of a network. In this sense, one of the unique contributions of this article is that the characteristics of European Research and Innovation Network will be linked with the innovation performance of the countries from Boltzmann's and Prigogine's views on entropy. In short, a simple rule is set forth based on Boltzman's view, and based on Prigogine's view, the innovation performance of Europe vis-à-vis its competitors will be discussed in order to produce policy recommendations for increasing the innovation performance of Europe and the improvement of the ERA's performance.

\section{Analysis and Results}

\section{Network Structure}

Since FP1, the European Union has been promoting and supporting research and development collaborations by bringing together organizations in related fields to turn ideas into new products,

\footnotetext{
Cited from: http://cordis.europa.eu/guidance/home_en.html, accessed 19.02.2016.
} 
services, and solutions in order to improve competitiveness. This support is based on the basic reason that knowledge is not solely the most valuable resource and the source of competitive advantage [Kogut, Zander, 1992], but also is produced by combining previously unconnected knowledge, generating new knowledge and by exchanging knowledge among actors. In short, knowledge production is a social process and it can be produced through the interactions of actors rather than as a creative act of a single individual or organization [Hakansson, 1989; von Hippel, 1988]. Such assumptions led the researchers to analyze networks in order to understand the role of network structure in facilitating exchanges, combinations, and the creation of knowledge [Kogut, Zander, 1992; Tsai, 2002; Tsai, Ghoshal, 1998).

A number of studies analyzed the networks established under the FPs. Roediger-Schluga \& Barber [Roediger-Schluga, Barber, 2006] focused on the structure of R\&D collaboration networks in the first five FPs, and found characteristics of complex networks. Breschi \& Cusmano [Breschi, Cusmano, 2002] dwell on the R\&D network established during FP3 and the first part of FP4. Investigating the network with the help of social network analysis and graph theory, they found the existence of small-world and scale-free characteristics. Protogerou et al. [Protogerou et al., 2010] concentrated on R\&D collaboration networks in the field of Information Society Technologies (IST) during FP4, FP5 and FP6. They found the existence of small-world structure as well as preferential attachment. All these studies focus on the projects and participants as nodes to determine the network structure. However, in this study, countries and regions (NUTS-2) will be considered the nodes upon which the network will be established, the links will be the R\&D projects.

Based on the reviewed literature, relationships between the number of participants, average timeframes, cost and funding of projects are also investigated. Correlation coefficients calculated among those that are shown in Table 1. As per the results, the rise in the number of participants have higher positive effects on the number of projects, as well as average duration, cost and funding. Furthermore, the increase in the number of partners in a project is in line with the recommendations made by evaluation studies of the FPs, highlighting the importance of simplifying administrative procedures.

The results obtained at the regional (NUTS-2) and country level (open network) networks are depicted in Table 2 and Table 3, respectively. An analysis of the data shows that starting from FP1, most regions or countries entered the network by connecting to central regions or countries. In both types of networks we see an increase in average betweenness centrality and a fall in average closeness centrality values, which can be accepted as an indication of increasing social capital [Borgatti et al., 1998]. The notion of path dependency can help explain this situation: successful project management capabilities and experience acquired in the past allow those actors to become coordinators or participants in future projects and helps them reduce the marginal cost of each additional project. Furthermore, the acquired visibility or reputation makes them attractive partners for newcomers demonstrating preferential attachment. Finally, experience in past projects may also decrease the transaction cost among partners in subsequent partnerships, which has the potential to augment mutual trust and understanding and therefore improve collaboration.

As a result, the shared characteristics of both networks such as scale-free degree distributions, relatively low average path length, high clustering, low assortativity values, etc., throughout the FPs in both networks, may be accepted as unchanging characteristics of network formation mechanisms, despite changes in FP rules. All networks show small-world characteristics, have relatively high clustering coefficients and short path lengths, meaning the structure of the network supports knowledge creation and knowledge diffusion [Cowan, 2004]. An analysis of participants in FPs reveals that same organizations participate repeatedly in FPs and continue to cooperate with each other after the conclusion of the project. Furthermore, increasing clustering coefficients in FPs in both networks demonstrates that the creation and integration of the ERA has been in line with the intended purpose.

\section{Network Structure and Innovativeness}

As discussed above, the stimulation of innovation is one key concern of policymakers at all levels. Correspondingly, the development and implementation of network policies may be regarded as a tool to overcome network failures [Nooteboom, Stam, 2008]. In other words, connecting actors through links to provide an exchange of information, knowledge, etc. can be seen as an appropriate policy within the framework of the systems of innovation approach [Carlsson, Jacobsson, 1997]. Therefore, in addition to

Table 1. Correlation Coefficient among Number of Participants, Average Duration, Cost, and Funding

\begin{tabular}{|l|c|c|c|c|c|}
\hline & $\begin{array}{c}\text { Number of } \\
\text { Participants }\end{array}$ & $\begin{array}{c}\text { Number of } \\
\text { Projects }\end{array}$ & $\begin{array}{c}\text { Average Duration of } \\
\text { Projects }\end{array}$ & $\begin{array}{c}\text { Average Cost of } \\
\text { Projects }\end{array}$ & $\begin{array}{c}\text { Average Funding of } \\
\text { Projects }\end{array}$ \\
\hline Number of Participants & 1.00 & & & & \\
\hline Number of Projects & 0.74 & 1.00 & & & \\
\hline $\begin{array}{l}\text { Average Duration of } \\
\text { Projects }\end{array}$ & 0.79 & 0.45 & 1.00 & 1.00 & \\
\hline Average Cost of Projects & 0.82 & 0.36 & 0.55 & 0.97 & 1.00 \\
\hline $\begin{array}{l}\text { Average Funding of } \\
\text { Projects }\end{array}$ & 0.78 & 0.33 & 0.55 & & \\
\hline \multicolumn{5}{|l}{ Source: calculated by the authrs. } \\
\hline
\end{tabular}




\section{Table 2. Network Characteristics (Regional Level)}

\begin{tabular}{|c|c|c|c|c|c|c|c|}
\hline Graph Metric & FP1 & FP2 & FP3 & FP4 & FP5 & FP6 & FP7 \\
\hline Graph Type & \multicolumn{7}{|c|}{ Undirected } \\
\hline Vertices & 189 & 223 & 271 & 281 & 298 & 309 & 322 \\
\hline Unique Edges & 1195 & 2166 & 3137 & 4230 & 5187 & 5359 & 5421 \\
\hline Edges With Duplicates & 2487 & 11751 & 14472 & 33291 & 41352 & 44510 & 60877 \\
\hline Total Edges & 3682 & 13917 & 17609 & 37521 & 46539 & 49869 & 66298 \\
\hline Self-Loops & 218 & 878 & 833 & 1987 & 3746 & 2337 & 3572 \\
\hline Average Geodesic Distance & 2.14 & 1.92 & 1.94 & 1.83 & 1.79 & 1.82 & 1.80 \\
\hline Graph Density & 0.10 & 0.17 & 0.16 & 0.24 & 0.26 & 0.25 & 0.25 \\
\hline Assortativity (wh) & -0.011 & -0.017 & 0.003 & 0.015 & 0.035 & 0.018 & 0.004 \\
\hline Average Degree & 19.429 & 38.278 & 44.266 & 67.480 & 77.054 & 77.974 & 81.814 \\
\hline Average Clustering Coefficient & 0.4690 & 0.6323 & 0.6322 & 0.6888 & 0.6850 & 0.6761 & 0.6801 \\
\hline Power Law & 3.12 & 2.60 & 2.58 & 2.20 & 2.40 & 2.28 & 2.37 \\
\hline Average Betweenness Centrality & 108.45 & 102.71 & 127.66 & 117.53 & 117.98 & 127.62 & 130.01 \\
\hline Average Closeness Centrality & 0.0025 & 0.0024 & 0.0019 & 0.0020 & 0.0019 & 0.0018 & 0.0018 \\
\hline
\end{tabular}

the networks explained in the previous section, a third type of the European Research and Innovation Network, a closed network was established with the countries listed in IUS 2013 and participated in the FPs. To assess the effect of project participation on innovation performance, the correlation values obtained between the number of projects and innovation performance values both at the country and NUTS-2 regional levels were calculated. According to correlation results, about half of the innovation performance of nodes (country and region) can be linked by the number of projects in which they participated.

Innovation performance and clustering values of countries in these three types of networks are correlated in order to analyze the relationships between innovation and clustering values of nodes (country or region). A negative correlation is found between innovation performance and clustering values at the regional and country levels (for instance, correlation coefficients between innovativeness values and clustering values in 2011 are -0.4266 with 00183 ( $p$ value); -0.6226 with 0.00008 ( $p$ value); and -0.43965 with 4.268 ( $p$ value) for closed, open and regional scale networks, respectively). Important gatekeepers at the country level in FP7 (Germany, France, Italy, and United Kingdom) are interested in identifying the countries filling structural holes and playing critical roles in bringing closed and open networks together. Then, the innovation performance value of countries and number of FP7 projects of countries are correlated with the important actors enumerated in IUS 2013 (Brazil, Canada, China, India, Japan, South Korea, Russia, the United States, and South Africa). According to the results, the average correlation coefficient is 0.4431 (for each year, $p$ values are found lower than 0.01137 ). Based on above findings, it may be said that collaboration with important rivals is significant for increasing the innovation performance of Europe. Furthermore, with regards to the role of the most important gatekeepers (Germany, France, Italy and United Kingdom), it seems they are the main actors not only in terms of knowledge production, but also for knowledge exchange between closed and open networks.

Table 3. Network Characteristics (Open Network)

\begin{tabular}{|c|c|c|c|c|c|c|c|}
\hline Graph Metric & FP1 & FP2 & FP3 & FP4 & FP5 & FP6 & FP7 \\
\hline Graph Type & \multicolumn{7}{|c|}{ Undirected } \\
\hline Vertices & 21 & 67 & 111 & 139 & 144 & 152 & 168 \\
\hline Unique Edges & 21 & 96 & 177 & 339 & 316 & 416 & 437 \\
\hline Edges With Duplicates & 3490 & 12830 & 20700 & 45013 & 51952 & 57237 & 74439 \\
\hline Total Edges & 3511 & 12926 & 20877 & 45352 & 52268 & 57653 & 74876 \\
\hline Self-Loops & 796 & 2297 & 3694 & 6899 & 7247 & 8158 & 11281 \\
\hline Average Geodesic Distance & 1.56 & 2.22 & 2.17 & 1.99 & 2.01 & 1.98 & 2.00 \\
\hline Graph Density & 0.44 & 0.10 & 0.07 & 0.10 & 0.10 & 0.12 & 0.11 \\
\hline Assortativity (wh) & -0.011 & -0.037 & -0.009 & -0.049 & -0.023 & -0.022 & -0.016 \\
\hline Average Degree & 10.000 & 7.164 & 8.234 & 13.525 & 14.667 & 17.842 & 18.619 \\
\hline Average Clustering Coefficient & 0.7862 & 0.6008 & 0.5987 & 0.7744 & 0.7755 & 0.7466 & 0.7616 \\
\hline Power Law & 0.94 & 2.39 & 2.97 & 2.93 & 2.77 & 2.84 & 3.02 \\
\hline Average Betweenness Centrality & 6.38 & 41.46 & 65.50 & 69.30 & 73.37 & 74.61 & 84.87 \\
\hline Average Closeness Centrality & 0.0320 & 0.0069 & 0.0042 & 0.0037 & 0.0035 & 0.0034 & 0.0030 \\
\hline
\end{tabular}


As stated above, starting from FP1, the average degree value of nodes increases; indicating that the capacity of countries is increasing in terms of maintaining links with others. The increase in average degree of nodes not only provides links between previously unconnected nodes, but may also bring about difficulties when finding appropriate links or ways to reach partners, information, knowledge, etc. For instance, studies in the field of supply networks [Choi et al., 2001], and in the biotechnology sector [Rycroft, 2007], found out that increased connectivity was not linearly related with an increase in efficiency, which is measured by delivery time and product development time, respectively. However, it has been found that there is a positive correlation between innovation and the degree values of nodes in the three types of network (for instance, correlation coefficients between innovativeness values and degree values in 2011 are 0.4483 with 0.01 ( $p$ value); 0.5690 with 0.0005 ( $p$ value); and 0.6801 with 0.01 ( $p$ value) for closed, open and regional level networks, respectively).

As stated earlier, the rise in the number of project partners may be in line with recommendations from evaluation studies [Expert Group, 2010] that emphasize the significance of curtailing administrative procedures. On the other hand, this may potentially have a negative effect on project performance, as the increase in the number of partners in a project will probably decrease the probability of interactions among the partners and building trust becomes more difficult. For instance, Lundvall et al. [Lundvall et al., 2002] argued that successful innovation is an outcome of interactive learning processes based upon close relationships between actors. Ruef [Ruef, 2002] and Powell et al. [Powell et al., 1996] discussed the importance of the number of actors in enabling the combination of different information, knowledge, resources, etc. On the other hand, Tatikonda and Rosenthal [Tatikonda, Rosenthal, 2000] assert that there are negative effects stemming from project size on innovation, though they could not provide strong empirical evidence for their argument. Furthermore, the role of different actors in innovation is widely discussed [Nooteboom, 2000; Ruef, 2002, etc.]. In general, it is presumed that diverse partners bring the latest information, knowledge, and resources into the project, increasing the success of innovative activity. Therefore, correlations between average project size (number of participants) and innovative value between the years 2006-2012 were made in order to assess their relationships. As per the result $(-0.6494)$, there is an inverse relationship between the project size and innovative value.

Moreover, the role of different types of actors in collaborative projects was also analyzed. Accordingly, between the years 2006-2012, the amount of cooperation by each country with others was calculated in order to analyze the notion of participant diversity in projects. Contrary to the inverse relationship between the project size and innovation performance value, a positive correlation was found between innovation performance and the diversity of partners, with an average correlation coefficient of 0.4105 (for each year, except for 2006, $p$ values are found lower than 0.0572).

In order to visualize the analysis of the aforementioned network relationships, heat maps at the country and regional (NUTS-2) levels were generated and analyzed. The heat map of each country or region was determined according to the total number projects, in which the country or region in question participated throughout all FPs (Figure 1 and Figure 2). These two tools of analysis reveal some interesting findings. Accordingly, if two nodes, countries, or regions, previously participated in a project, they show an inclination to participate in new projects together. Moreover, there is also a tendency to participate in a new project with the previous coordinator.

\section{The European Research Area}

The ERA can be understood as integrated countries or regions collaborating within networks while competing for markets. In line with the above discussion, the ERA should be designed, developed and implemented in order to create synergy, competition, and cohesion, instead of creating conflicts, among actors. As such, to what extent the ERA is complete and how it supports the European Research and Innovation Network was analyzed. A negative correlation was assumed between the geographical distances of the project partners and the intensity of the interaction among project partners, as it is assumed that an increase in the distance between two partners will decrease the probability of those becoming partners in a project [Hoekman et al., 2007]. In brief, the findings reveal that:

1. Regions (NUTS-2) and countries prefer collaborating with those nearby, implying that geographical distance is still an important factor in the selection of partners for research activities.

2. Scale-free structure of network indicates that nodes prefer to collaborate with nodes that have more links, instead of periphery nodes or lagging nodes. On the other hand, this situation suggests that periphery nodes or lagging nodes could not enter the 'network of excellence', and disparities between these two will only increase [Clarysse, Muldur, 2001].

3. Regions (NUTS-2) prefer to collaborate with domestic partner(s) rather than 'foreign' ones, entailing that institutional infrastructure (norms, values, etc.) and national policies such as taxes, labor, funding, etc., are still important factors in selecting partner(s) for research activities.

As shown in Figure 3 and Figure 4, the importance of distance increases from the east of Europe to the west in both networks. Western Europe, as well as some parts of Northern Europe give much more importance to the notion of distance. These nodes are also important actors for the competitiveness and innovation performance of Europe. As a result, the ERA is not complete because proximity is still an important factor for nodes in their selection of partners. Moreover, with regards to the aforementioned finding, it is assumed that if an increase in the number of nodes is higher than the increase in the selfloops value, which demonstrates the existence of a project participant in the same regions more than 


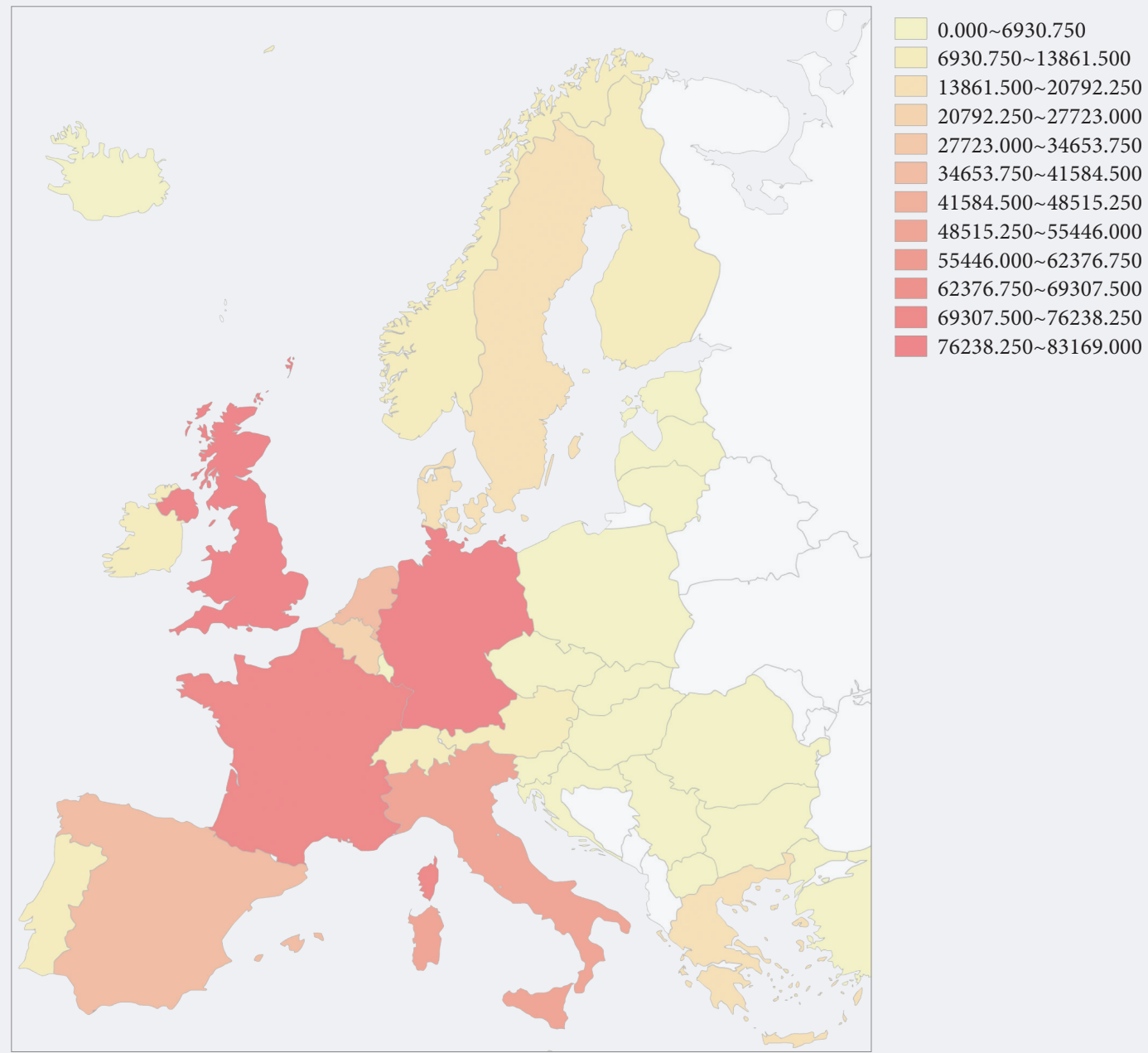

Source: compiled by the authors.

once, regions can be said to prefer collaborating with domestic partner(s) instead of 'foreign' ones. The results show that while the number of partners increases 0.70 -fold from FP1 to FP7, the increase in selfloops is 15.38 -fold from FP1 to FP7.

The ERA can be considered a useful tool for removing artificial barriers related to geography and borders. Moreover, it helps establish networks among organizations, advanced regions and countries, which are important components for increasing the competitiveness and innovation performance of Europe on a global scale. However, they can also deepen discrepancies among organizations, regions and countries, which undermine the social sustainability of the system due to the unintended negative consequences of innovation policies. Thus, this dual structure, which increases both competitiveness and discrepancies, should be accepted as the result of unavoidable outcomes of the programs and policies related to the ERA. A positive correlation between the number of projects and innovation performance value of nodes can be regarded as indicators for the existence and/or development of the ERA. The research area is based upon European integration at the regional, national and continental levels in accordance with the Lisbon Agenda, which aims to improve European competitiveness by developing collective innovation and research capabilities of Europe as a whole. The European Commission is proceeding based on the assumption that this dual structure will be eradicated over time, given that those lagging regions will increase their knowledge base, innovation performance, and competitiveness over time with the help of funding. However, findings show the clear trend of preferential attachment. That is, nodes prefer to collaborate with nodes having more links instead of periphery or lagging nodes. Therefore, as one of the contributions of this article, it can be said that improving the knowledge base, innovation performance, competitiveness, and so on is necessary but not sufficient; the periphery or lagging regions and countries still must pass a threshold to become attractive partners for FP projects or the European research network. 


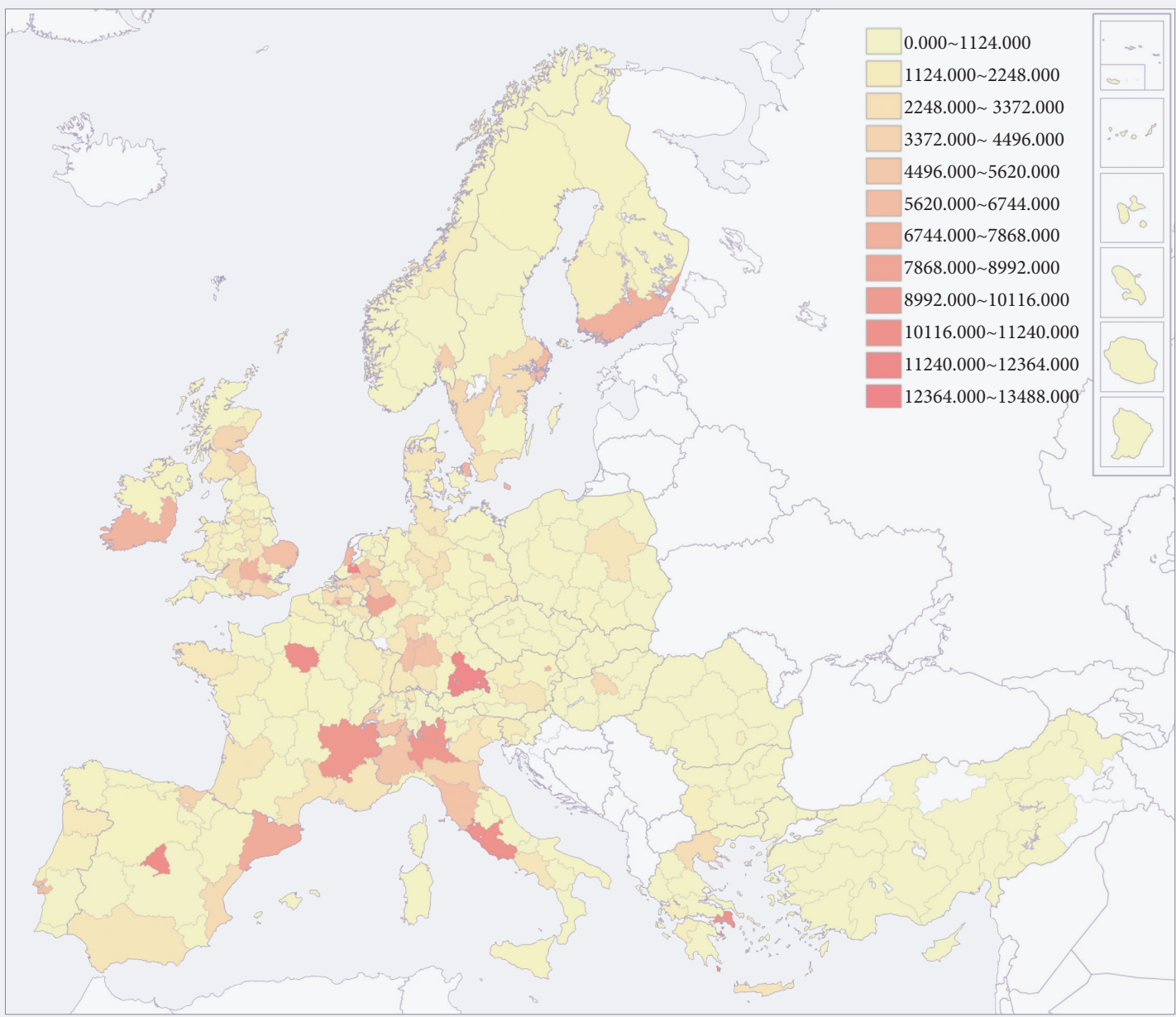

Source: compiled by the authors.

Accordingly, the related literature also underlines the difficulty of entering a scale-free network due to preferential attachment, and entering small-world type of networks due to the difficulty of attaining access to closed networks or cliques. As explained in [Uzzi, Spiro, 2005; Fleming et al., 2007; Schilling, Phelps, 2007], cliques have strong ties with each other, making it difficult to introduce new information and knowledge or persuade members of cliques to implement new mechanisms. Furthermore, as mentioned above, it is found that as the value of average degree rises, implying that the capacity of regions (NUTS-2) and countries increases in terms of maintaining links with others. When the increase in the number of unique and duplicated links among the nodes are analyzed, the increase in the ratio of duplicate values is observed to be much higher than that of unique values, demonstrating that vertices (regions and countries) primarily prefer to establish links with the existing nodes, instead of new ones.

This situation has positive and negative sides, depending on the vantage point. While it may be regarded as the establishment of a main structure of FP networks or declining transaction costs among the partners with the contribution of the EU, This may also be seen as a situation, in which, the same actors, doing the same thing with different tools receive support with only a few transforming into well-known reference companies in the world as an outcome in the processes. Put differently, while this process increases the sustainability of the structure, at the same time, it potentially can simultaneously reduce the opportunities for newcomers. As such, it may be speculated that this relatively semi-locked network (or the notion of path dependency), teaming up with previous partners, may not only lead to redundancy, but also trigger risks of lock-in [Leonard-Barton, 1992]. That is to say, it is difficult for latecomers, which may be an organization, region or a country, to form a hub because of the network structure, which may hamper the re-orientation of relations in the network towards more productive research areas. 


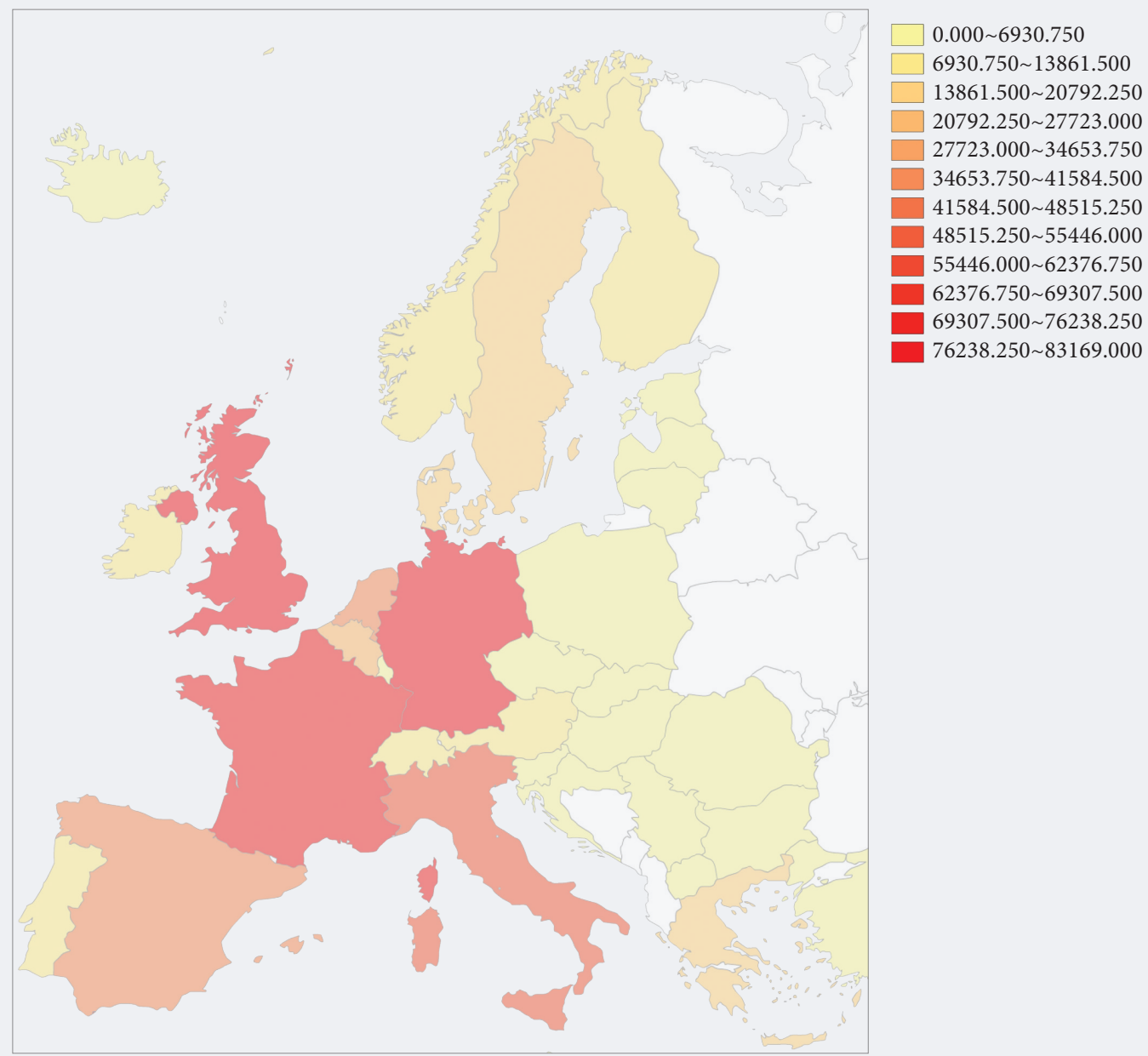

Source: compiled by the authors.

\section{Network Structure, Entropy, and Innovation Performance}

In line with the discussion on Boltzmann's entropy, the possibility of achieving innovation is lower when inputs of innovation are concentrated in a single country, organization, or region, while it is higher if they are distributed among various entities. Inputs such as human resources, research systems, firm investments, etc., which have different values are distributed differently among countries in IUS 2013. For instance, the value of 'firm investments' (composed of business R\&D expenditure and non-R\&D expenditures on innovation) for the year 2012 is 0.287 in Italy and 0.417 in Belgium, indicating the probability of finding a firm investing in R\&D and non-R\&D for innovation is higher in Belgium than Italy. As explained above, the distribution cannot be changed; in accordance with the even distribution of probabilities among nodes. On the other hand, the existence of competition among countries does not permit a concentration of probabilities. This leaves only one alternative, upon which policies can be developed.

Several researchers argued that links in networks are important means for exchanging information, knowledge, resources, etc. [Ahuja, 2000; Powell et al., 1996; Leoncini et al., 1996; Ter Wal, Boschma, 2011], which are important components for new combinations [Nelson, Winter, 1982] and innovations. In this framework, the position of an actor is an important factor in determining its innovation performance [Schilling, Phelps, 2007]. As discussed by Singh [Singh, 2005], by influencing the structure of network, policymakers may increase not only the information, knowledge and capabilities of the actors, but also the ability of actors to innovate.

When the relationship between the structure of the network established by FPs and innovation performance values are analyzed, the correlation results given in Table 4 are obtained for the three types networks. In Table 4, innovation performance value shows the highest correlation with the eigenvector 


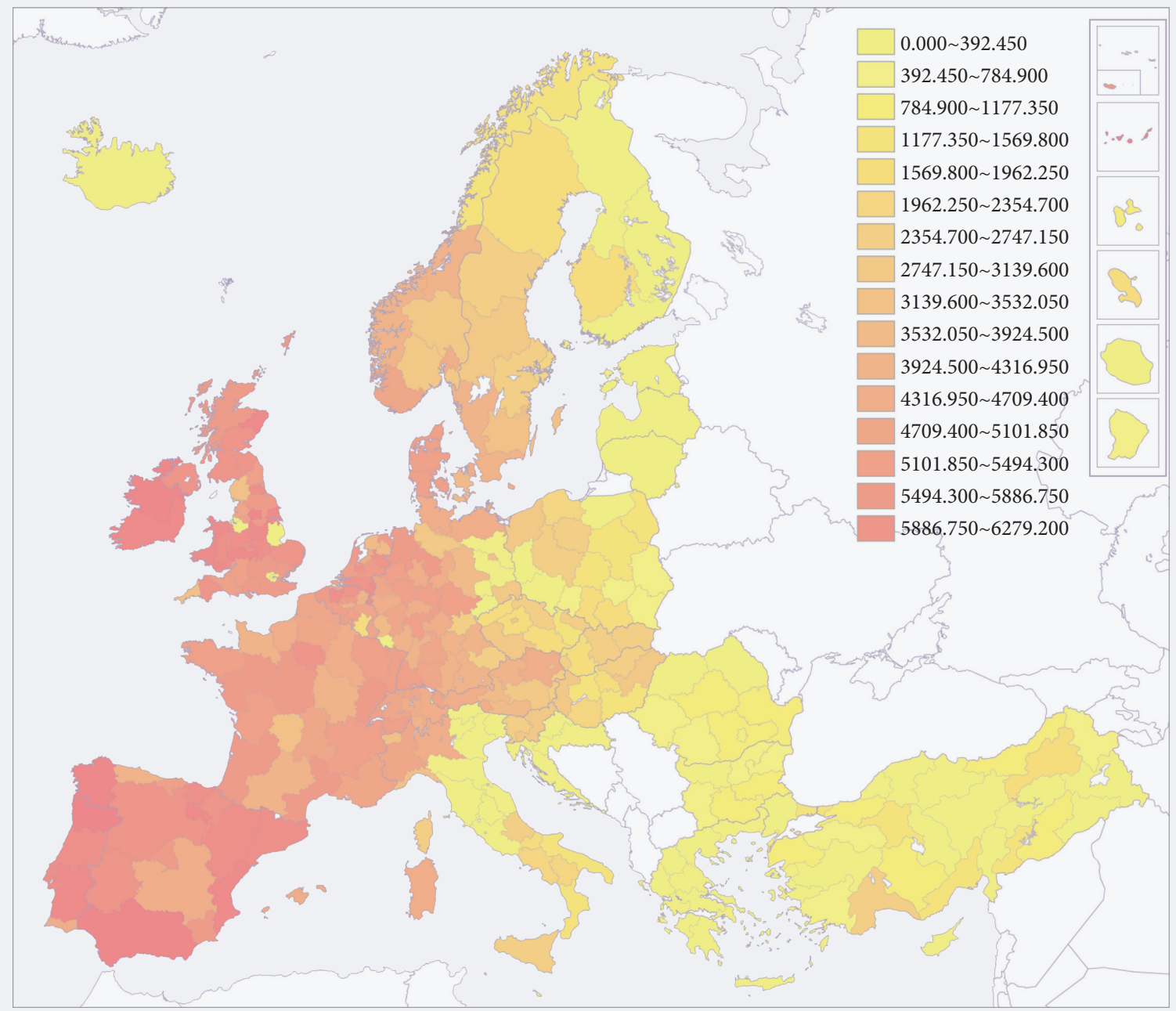

Source: compiled by the authors.

value denoting a node's importance in a network based upon the node's connections, and next, with the degree values in country networks, either open or closed, in a regional network. As per the discussions above, it does not make sense to expect a redistribution of links among the countries for obtaining high degree values in order to make positive contributions to the innovation performance of the countries. On the other hand, the eigenvector value may be taken into consideration as a tool for policy intervention. That is, the inclusion of a node with a low eigenvector value in a project consortium not only enables the establishment of a consortium with the preferred partners, but also supports the existing degree distribution, which contributes to the competitiveness of Europe.

The last statement is also supported by Demetrius \& Manke, who suggest "[w]hile robustness is defined as the resilience of the network against changes in the underlying network parameters, network entropy characterizes its pathway diversity" [Demetrius, Manke, 2005]. As such, in an unweighted and undirected network (like the networks established in this article), topological entropy can be calculated using the Kolmogorov-Sinai formula for entropy, according to which, topological entropy is positively correlated with the largest eigenvector value of the network. In this framework, the largest entropy value among all nodes in FPs is found and correlated with the innovation performance value of Europe. The correlation coefficient between them is -0.052 , meaning that they are almost uncorrelated.

Next, the most relevant eigenvector value according to the argument of Demetrius \& Manke [Demetrius, Manke, 2005] was investigated and it was found that average eigenvector centrality is most correlated with innovation performance, which is -0.8379 . This indicates an inverse relationship between average eigenvector centrality and innovation performance: a decreased average eigenvector centrality yields a higher innovation performance value. The network structure results is characterized not only by the configuration of nodes and sectors, but also by the interactions between the components of the institutional infrastructure, as discussed by Kogut [Kogut, 2000]. In this sense, the position and links of 
Table 4. Correlation Coefficients of Average Network Characteristics and Innovativeness

\begin{tabular}{|l|l|l|l|l|l|l|}
\hline Closed Network & $\mathbf{2 0 0 7}$ & $\mathbf{2 0 0 8}$ & $\mathbf{2 0 0 9}$ & $\mathbf{2 0 1 0}$ & $\mathbf{2 0 1 1}$ & $\mathbf{2 0 1 2}$ \\
\hline Degree & 0.4729 & 0.3248 & 0.3429 & 0.4069 & 0.4483 & 0.4392 \\
\hline Betweenness Centrality & 0.2499 & 0.0213 & 0.2240 & 0.2593 & 0.3916 & 0.4507 \\
\hline Closeness Centrality & 0.4668 & 0.3365 & 0.3482 & 0.4296 & 0.4609 & 0.4497 \\
\hline Eigenvector Centrality & 0.4763 & 0.3238 & 0.3348 & 0.3912 & 0.4336 & 0.4167 \\
\hline Clustering Coefficient & -0.0307 & -0.2151 & -0.2730 & -0.3759 & -0.4265 & -0.4755 \\
\hline Open Network & $\mathbf{2 0 0 7}$ & $\mathbf{2 0 0 8}$ & $\mathbf{2 0 0 9}$ & $\mathbf{2 0 1 0}$ & $\mathbf{2 0 1 1}$ & $\mathbf{2 0 1 2}$ \\
\hline Degree & 0.5967 & 0.5873 & 0.5807 & 0.5638 & 0.5690 & 0.5455 \\
\hline Betweenness Centrality & 0.4371 & 0.4054 & 0.4138 & 0.3793 & 0.3896 & 0.3739 \\
\hline Closeness Centrality & 0.5694 & 0.5519 & 0.5476 & 0.5383 & 0.5453 & 0.5246 \\
\hline Eigenvector Centrality & 0.5810 & 0.6078 & 0.6143 & 0.6047 & 0.6037 & 0.5694 \\
\hline Clustering Coefficient & -0.6782 & -0.6573 & -0.6328 & -0.6154 & -0.6226 & -0.5905 \\
\hline Regional Network & $\mathbf{2 0 0 7}$ & & $\mathbf{2 0 0 9}$ & & $\mathbf{2 0 1 1}$ & \\
\hline Degree & 0.5916 & & 0.6445 & & 0.6801 & \\
\hline Betweenness Centrality & 0.4131 & & 0.4043 & & 0.4262 & \\
\hline Closeness Centrality & 0.6474 & & 0.6409 & & 0.6734 & \\
\hline Eigenvector Centrality & 0.6135 & & 0.6637 & & 0.6949 & \\
\hline Clustering Coefficient & -0.0617 & & -0.2423 & & -0.4396 & \\
\hline Source: calculated by the authors. & & & &
\end{tabular}

the node determine its eigenvector value. Therefore, it is not possible to demand that nodes (countries or regions) change the links they have, to integrate the nodes with low eigenvector values into the networks. Instead, a policy developed upon eigenvector in his study may be implemented in a manner that allows the nodes with low eigenvector values to be taken into the networks. In the case of such a situation, the eigenvector value pertaining to both the countries with previously low and high eigenvector values will change accordingly.

The choice of strategy is determined by the eigenvector distribution of each node in the network. It was found that eigenvector values of nodes are in accordance with the power law value of the network (correlation coefficient is 0.7888 with $\mathrm{p}=0.03$ ). Furthermore, there is an inverse relationship between the innovation performance and power law value, indicated with a correlation coefficient value of -0.5247 . As an emergent structure, we cannot trade the innovation performance of Europe for the characteristics of a network, implying that instead of deciding who will establish a network, a simple rule may be added to the application process, which may bring about a more democratic distribution (or lower power law value) and more innovation.

Another interesting finding is the relationship between the European Research and Innovation Network and the entropy of the system. Based on discussions by Prigogine \& Stengers [Prigogine, Stengers, 1984], it can be stated that entropy of an isolated system never decreases due to the second law of thermodynamics and thus, we observe a lock-in or entropic death [Saviotti, 1988]. In this sense, the average degree value of countries consisting of non-members, candidates and EFTA members is 969.71 between the years 2006-2012, meaning that the European Research and Innovation Network clearly maintains its links with outside entities. However, this statement is no more than stating the obvious in terms of the relationship between entropy and the European Research and Innovation Network. The critical point here is the analysis of the relationships between the European Research and Innovation Network and degree values of important rivals, as stated in the Innovation Union Scoreboard 2013 (IUS) report. Essentially, the changes in the innovation performance value of Europe, stated in IUS 2013, and in degree values of each important rival from successive years (2006-2007, 2007-2008, etc.) are calculated. In this framework, it is assumed that a positive correlation value will be obtained if the relationships between the European Research and Innovation Network and its important rivals have a positive effect on innovation performance of Europe, or vice versa. Correlation results obtained between the innovation performance value of Europe and the degree values of important rivals are given in Table 5.

According to IUS 2013, the United States, South Korea, and Japan have a performance lead over Europe; while Brazil, Canada, China, and Russia lag behind. The obtained results given in Table 6 are consistent with IUS 2013 statements, demonstrating a positive correlation between Europe and Brazil, Canada, China, and Russia; and a negative correlation between Europe and the United States, South Korea, and Japan. Put differently, when its relations with three of its rivals are considered, the existing policy and implementations in Europe have not proved as beneficial as expected. 
Table 5. Correlation Coefficients between Changes in Average Innovation Performance Value of Europe and changes in Degree Values of Important Rivals

\begin{tabular}{|l|c|}
\hline \multicolumn{1}{|c|}{ Countries } & Innovation Performance \\
\hline Brazil & 0.87 \\
\hline Canada & 0.78 \\
\hline China & 0.02 \\
\hline India & - \\
\hline Japan & -0.99 \\
\hline South Korea & -0.99 \\
\hline Russia & 0.06 \\
\hline United States & -0.89 \\
\hline Source: calculated by the authors. & \\
\hline
\end{tabular}

\section{Policy Recommendations}

The dual structure (competition and cohesion), resulting from the implementation of projects related to the ERA, should be considered when ERA policy is developed, so that all of the EU rather than only the most successful participants benefit. However, the discussion on the ERA based on the obtained results proved that the ERA has not yet been completely established [European Commission, 2012]. The European Commission states that the "ERA is at the heart of the Europe 2020 strategy and its Innovation Union (IU) policy flagship and why the European Council has called for ERA to be completed by 2014" [European Commission, 2012]. Since, it is thought that one way or another, the fulfillment of the ERA will provide harmony among the policymakers in terms of not only their perception and implementation of SIs policies, but also eliminate or at the very least minimize concerns and disagreements stated above. When the relationship between network structure established by FPs and innovation performance values were analyzed, it was found that innovation performance shows the highest correlation with the eigenvector value and then with the degree values in either open or closed country or regional networks. Based on the explanations above one should not count on a redistribution of links among the countries in order to improve the innovation performance of countries. As such, the European Commission may decide on the duration of support, the amount of a project's budget, the amount of project funding, and the types of participants. However, as a network is an emergent structure, even if the high clustering or low path length have positive effects on the dissemination and production of information and knowledge, the Commission should not decide who will work on the project. Therefore, in terms of cohesion, the eigenvector value may be considered a tool for policy intervention.

Given the emergent structure of the European Research and Innovation Network and the importance of current nodes, which can be either a country or a region, for the innovation performance and competitiveness of Europe, the European Commission may introduce a simple rule. For the project application process, it may stipulate the inclusion of a node with a low eigenvector value in the project consortium. This would both allow for the free establishment of said project consortium, and facilitate the participation of nodes with low innovation performance in the network. That is, when the sustainability of EU innovativeness is considered, managing the increase in diversity without leading to a decrease in the system performance, is a question to be answered by EU policymakers. This study suggests using an eigenvector calculation as a simple but effective tool for increasing the cohesion of a region or country in order to build the Innovation Union, including the ERA. Participation in FP projects will gradually increase the knowledge base of periphery and lagging regions or countries. One may ask whether there is a negative side to the inclusion of periphery and lagging regions or countries in a project in terms of the overall innovation performance of the EU, or leader regions or countries. As stated earlier, this rule does not prevent any partners from establishing a project consortium with others. In other words, at least one node, which has a lower eigenvector value, will be included in a project consortium, and the rest of project partners will be selected according to the free will of the applicants (project leader or coordinator) of the project.

The problem of cooperation is tied to the issue of the EU's competitiveness. As mentioned, there are enough links among the nodes (regions and countries) to prove that nodes are able to collaborate with others. Concerning the competitiveness of $\mathrm{EU}$, with regards to the role of the most important gatekeepers (i.e. actors filling structural holes), it is found that they are the main actors not only in terms of knowledge production and diversity, but also for knowledge exchanges between closed and open networks, or between the EU and other regions. However, when relations with the three most important competitors are considered, the existing policy and project implementations have not proven as beneficial as expected by the architects of the European Research and Innovation Network. Put differently, based on the finding that indicates a negative correlation between the clustering coefficient and innovation performance, and a partially positive correlation between the number of projects with important rivals and innovation performance, it may be stated that collaboration with important competitors is a significant factor in boosting innovation performance in Europe. Instead of focusing on obtaining high clustering, which may also indicate the existence of redundant links among nodes, a decrease in differences, etc., focusing 
on structural holes may be considered an alternative for increasing innovation performance in the EU. Therefore, regarding the ability of important gatekeepers to connect with global networks but the low absorptive capacity of the system in terms of benefiting from those rivals, it is logical to propose that policy makers of the EU focus more on the development of diversity and absorptive capacity of nodes in order to benefit more from the European Research and Innovation Network to increase the EU's innovation performance.

Evidently, the preferred tools in the implementation of the aforementioned recommendations are a critical issue. The selection of policy tools forms a part of the policy formulation and they are actually part of the policy implementation itself. Notwithstanding which policies and tools related with innovation are selected, their framework and impact are mainly determined by the ultimate political objectives, which might be related to various topics ranging from economic issues such as growth, employment, and inflation, to social, environmental and defense concerns. Furthermore, selection and implementation of appropriate innovation policy tools depend on the causes behind the problems identified by the researchers, governing authorities, etc. The analysis in this study reveals two important causes, giving rise to the two main policy recommendations (Table 6), stated above. One of the causes is the imbalance among nodes (regions and countries in Europe) in terms of knowledge accumulation, capacities, and capabilities, which prevent the cohesion and development of the ERA and increase the innovation performance of the EU. The second is the low level of diversity and absorptive capacity of nodes, especially gatekeepers, preventing the rise of competitiveness in the ERA and adding to the innovation performance gap with the important rivals stated in IUS 2013, specifically the US, Japan and South Korea.

The regulatory, economic and soft tools [Borrás, Edquist, 2013] used for innovation policies, can be considered important means used by governing bodies for policy intervention. Within the scope of systems of innovation and network studies cited in this article, two instruments were selected in order to implement the suggested policy recommendations. One is in the framework of regulatory instrument in accordance with the classification by Borrás \& Edquist [Borrás, Edquist, 2013]. It stipulates that the inclusion of a node with a low eigenvector value in projects may be used for balancing nodes (regions and countries in Europe) in terms of knowledge accumulation, capacities, and resources for stimulating the cohesion and development of the ERA and innovation performance of the EU. The second tool falls into the category of economic or soft instruments. In order to increase the diversity and absorptive capacities of actors, specifically gatekeepers, vis-a-vis Europe's important competitors, which are listed in IUS 2013, this study considers the use of public procurements or public-private partnerships (PPP) for increasing the competitiveness of the ERA and decreasing the innovation performance gap with important rivals, specifically the US, Japan and South Korea. Given that the specific and complex projects, which are being implemented as part of a contract or in partnership with state agencies, facilitate the growth of specific knowledge and capabilities of actors, which furthermore increases the diversity as well as absorptive capacity of actors in line with the announced strategic targets.

As a result, Barca's report underlined the importance of a combined exogenous and endogenous push for institutional changes in nodes (country and/or region). While innovation policy, which supports advancements, deepens inequalities among the nodes, the cohesion policy facilitates measures to eliminate inequalities among the nodes [Barca, 2009]. In this sense, the recommendations developed in this study related to the cohesion and competitiveness of the ERA as well as the innovation performance of the EU could be seen as an appropriate input for developing institutional infrastructures in the nodes (country or region). In accordance with Prigogine's argument, while the European Research and Innovation Network, in a sense, draws resources for its development from the outside by improving its ability to manage links with non-EU countries, especially important rivals. At the same time, the eigenvector approach enables the EU's cooperation by increasing the absorption and diffusion of knowledge between nodes, especially lagging or periphery nodes. In this way, not only political concerns related to the effect of the hollowing out' of globalization on the innovation systems in Europe or with network failures [Varblane et al., 2007] can be diminished, but also global networks can be used for increasing the performance of systems of innovations at all levels.

\section{Contributions and Future Directions of Study}

As discussed by some of the authors [Arnold, 2011; Weber, 2010; Richardson, 2000; etc.], the bridge between network analysis and policy development should be established and this link should be used

\begin{tabular}{|l|l|l|}
\hline \multicolumn{2}{|c|}{ Table 6. Aims, Instruments, and Policy } \\
\cline { 2 - 4 } & \multicolumn{1}{|c|}{ Cohesion } \\
\hline \multicolumn{2}{|c|}{} & \multicolumn{1}{c|}{ Competitiveness } \\
\hline
\end{tabular}


for developing and implementing policy. That is, network analysis techniques should say more than the obvious results that can be obtained using mathematical operations, such as the changes in network sizes, the determination of the importance of actors by adding the number of projects they participated in, etc. The methodology developed in this study, which aimed to use network analysis in order to produce policy recommendations, will contribute to answering valid criticisms in the literature.

It is believed that this study might provide a base for two different types of studies for integrating network studies and policy development and implementation. The first type is an investigation into the relationship between the growth, collaboration and innovations in the European Union. The existing study already deals with the relationship between innovation and collaboration and a discussion on this relationship, combined with social capital and growth, will be able to contribute to the development of academic studies on trust, social capital, and innovation.

Another field of study is the analysis of network structure, the position of actors in it and the performance of nodes, either national or regional. Particularly in an environment where network formation is encouraged, the examination of network structure and the impact of performance in a network will contribute to programs such as FPs, which support network formations.

\section{Conclusion}

The European Research and Innovation Network, formed at three stages in this study, emerged as a result of policies implemented at the European level, was analyzed with the help of standard network analysis techniques to evaluate RTD (research, technology and development) policies, implemented by the European Commission. At the same time, discussions on entropy were combined with the results obtained from the analysis of the European Research and Innovation Network, and discussions on SIs, within the framework of the EC's projects related to the ERA and innovation performance of the EU. In this way, network analysis can be used not only as a component of policy recommendation, but as one of the unique contributions of the study. The innovation performance of Europe was discussed and policy recommendations were made using discussions and analyses of systems of innovation and network studies.

This approach yielded with two main policy recommendations. Firstly, the implementation of a simple rule - the inclusion of a node with a low eigenvector value in a project consortium by the EC will not only increase the cohesion process of the ERA but also the innovation performance of EU. Secondly, without forgetting the emergent structure of the European Research and Innovation Network and the importance of current nodes for innovation in Europe, it can be said that when relations with three of the most important rivals (the United States, South Korea, and Japan) are considered, the existing strategies and their implementation have not proven as beneficial as expected by the European authorities. In this sense, policymakers of EU should focus more on the development of diversity and absorptive capacity of nodes that form structural holes, in order to benefit more from the European Research and Innovation Network and increase the innovation performance of Europe.

We would like to thank M.T. Pamukcu, S. Akcomak and Y. Ustuner for their invaluable contributions in establishing a basis for the study and the members of the Science and Technology Policy Studies department at METU.

\section{References}

Ahuja G. (2000) Collaboration Networks, Structural Holes, and Innovation: A Longitudinal Study. Administrative Science Quarterly, vol. 45, no 3, pp. 425-455.

Allen P.M. (2001) A complex systems approach to learning in adaptive networks. International Journal of Innovation Management, vol. 5, no 2, pp. 149-180. DOI: 10.1142/s136391960100035x

Andersen E.S. (1996) From static structures to dynamics: Specialisation and innovative linkages. Economic Interdependence and Innovative Activity: An Input-Output Analysis (ed. C. de Bresson), Cheltenham, UK; Brookfield, US: Edward Elgar, pp. 331-353.

Andersen E.S. (1997) Innovation Systems: Evolutionary Perspectives. Systems of Innovation: Technologies, Institutions, and Organizations (ed. C. Edquist), London; Washington: Pinter, pp. 174-179.

Archibugi D., Denni M., Filippetti A. (2009) The Global Innovation Scoreboard 2008: The Dynamics of the Innovative Performances of Countries, Rochester, NY: Social Science Research Network.

Arnold E. (2011) Understanding the long-term impacts of the EU framework programme of research and technological development, Twente: University of Twente.

Asheim B.T., Gertler M.S. (2005) The geography of innovation: Regional innovation systems. The Oxford Handbook of Innovation (eds. J. Fagerberg, D.C. Mowery, R.R. Nelson), Oxford; New York: Oxford University Press, pp. 291-317.

Asheim B.T., Moodysson J., Tödtling F. (2011) Constructing Regional Advantage: Towards State-of-the-Art Regional Innovation System Policies in Europe? European Planning Studies, vol. 19, no 7, pp. 1133-1139.

Barca F. (2009) An Agenda for a Reformed Cohesion Policy: A Place-based Approach to Meeting European Union Challenges and Expectations, Brussels: Economics and Econometrics Research Institute (EERI).

Bar-Yam Y. (2003) Dynamics of Complex Systems, Boulder, CO: Westview Press.

Becattini G. (1990) The Marshallian industrial district as a socio-economic notion. Industrial Districts and Interfirm Cooperation in Italy (eds. F. Pyke, G. Becattini, W. Sengenberger), Geneva: International Institute for Labour Studies, pp. 37-51.

Borgatti S.P., Jones C., Everett M.G. (1998) Network measures of social capital. Connections, vol. 21, no 2, pp. $27-36$.

Borrás S., Edquist C. (2013) The Choice of Innovation Policy Instruments, Lund: Lund University, CIRCLE. 
Boltzmann L. (1974) The second law of thermodynamics (Populare Schriften, Essay 3, address to a formal meeting of the Imperial Academy of Science, 29 May 1886). Reprinted in Ludwig Boltzmann, Theoretical physics and philosophical problem (translated by S.G. Brush). Boston: Reidel (Original work published in 1886).

Breschi S., Cusmano L. (2002) Unveiling the Texture of a European Research Area: Emergence of Oligarchic Networks under EU Framework Programmes, Milano: Universita’ Bocconi.

Camagni R. (1991) Local 'milieu', uncertainty and innovation networks: towards a new dynamic theory of economic space. Innovation Networks: Spatial Perspectives (ed. R. Camagni), London: Belhaven Press, pp. 121-142.

Camagni R., Capello R. (2013) Regional Innovation Patterns and the EU Regional Policy Reform: Toward Smart Innovation Policies. Growth and Change, vol. 44, no 2, pp. 355-389.

Caracostas P., Muldur U. (1998) Society, the endless frontier: A European vision of research and innovation policies for the 21st century, Luxembourg: Office for Official Publications of the European Communities.

Carlsson B., Jacobsson S. (1997) Diversity creation and technological systems: A technology policy perspective. Systems of Innovation: Technologies, Institutions, and Organizations (ed. C. Edquist), London; Washington: Pinter.

Carlsson L. (2000) Policy Networks as Collective Action. Policy Studies Journal, vol. 28, no 3, pp. 502-520.

Choi T.Y., Dooley K.J., Rungtusanatham M. (2001) Supply networks and complex adaptive systems: Control versus emergence. Journal of Operations Management, vol. 19, no 3, pp. 351-366.

Clarysse B., Muldur U. (2001) Regional cohesion in Europe? An analysis of how EU public RTD support influences the techno-economic regional landscape. Research Policy, vol. 30, no 2, pp. 275-296.

Cooke P. (1996) The new wave of regional innovation networks: Analysis, characteristics and strategy. Small Business Economics, vol. 8,no 2,pp. 159-171.

Cowan R. (2004) Network models of innovation and knowledge diffusion, Maastricht: Maastricht Economic Research Institute on Innovation and Technology.

Das T.K., Teng B.-S. (2002) Alliance Constellations: A Social Exchange Perspective. The Academy of Management Review, vol. 27, no 3,pp. 445-456.

DeBresson C., Amesse F. (1991) Networks of innovators: A review and introduction to the issue. Research Policy, vol. 20, no 5, pp. 363-379.

Demetrius L., Manke T. (2005) Robustness and network evolution - An entropic principle. Physica A: Statistical Mechanics and Its Applications, vol. 346, no 3-4, pp. 682-696.

Dye T.R. (2012) Understanding Public Policy (14th edition), Boston: Pearson.

European Commission (1995) Green Paper on Innovation (COM (95) 688 final, 20 December 1995), Brussels: European Commission.

European Commission (1997) The first action plan for innovation in Europe. Innovation for growth and employment (COM (96) 589 final,20 November 1996), Brussels: European Commission.

European Commission (2000) Towards a European Research Area: Communication from the Commission to the Council, the European Parliament, the Economic and Social Committee and the Committee of the Regions (COM (2000)6), Luxembourg: Office for Official Publications of the European Communities.

European Commission (2006) An Innovation-friendly, Modern Europe: Communication from the Commission to the European Council (COM(2006)589, 20 October 2006), Luxembourg: Office for Official Publications of the European Communities.

European Commission (2010a) Communication from the Commission to the European Parliament, the Council, the European Economic and Social Committee and the Committee of the Regions Europe 2020 Flagship Initiative Innovation Union (COM(2010)546), Luxembourg: Office for Official Publications of the European Communities.

European Commission (2010b) The role of community research policy in the knowledge-based economy: Post-2010 strategies for research policies, Luxemburg: Publication Office of the European Union.

European Commission (2012) A Reinforced European Research Area Partnership for Excellence and Growth (COM(2012)392), Brussels: European Commission.

Expert Group (2010) Interim Evaluation of the Seventh Framework Programme, Brussels: European Commission.

Fagerberg J., Guerrieri P., Verspagen B. (eds.) (1999) The Economic Challenge for Europe: Adapting to Innovation Based Growth, Cheltenham; Northampton: Edward Elgar.

Flap H., Bulder B., Beate V. (1998) Intra-organizational Networks and Performance: A Review. Computational \& Mathematical Organization Theory, vol. 4, no 2, pp. 109-147.

Fleming L., King C., Juda A.I. (2007) Small Worlds and Regional Innovation. Organization Science, vol. 18, no 6, pp. 938-954.

Foray D. (2006) Economics of knowledge, Cambridge, MA; London: MIT.

Foray D., Lundvall B.-A. (1996) The Knowledge-Based Economy: From the Economics of Knowledge to the Learning Economy. Employment and Growth in the Knowledge-Based Economy, Paris: OECD, pp. 11-32.

Foray D., van Ark B. (2007) Smart specialisation in a truly integrated research area is the key to attracting more R\&D to Europe (Expert Group "Knowledge for Growth", Policy Brief no 1), Brussels: European Commission.

Freeman C. (1991) Networks of innovators: A synthesis of research issues. Research Policy, vol. 20, no 5, pp. 499-514.

Gereffi G., Humphrey J., Sturgeon T. (2005) The governance of global value chains. Review of International Political Economy, vol. 12, no 1, pp. 78-104.

Granovetter M. (1973) The Strength of Weak Ties. American Journal of Sociology, vol. 78, no 6, pp. 1360-1380.

Hagedoorn J. (1990) Organizational modes of inter-firm co-operation and technology transfer. Technovation, vol. 10 , no 1 , pp. $17-30$.

Hagedoorn J. (1993) Understanding the rationale of strategic technology partnering: Interorganizational modes of cooperation and sectoral differences. Strategic Management Journal, vol. 14, no 5, pp. 371-385.

Hakansson H. (1989) Corporate Technological Behaviour: Cooperation Networks, London; New York: Cengage Learning EMEA.

Hoekman J., Frenken K., van Oort F. (2007) Towards a European Research Area, Rotterdam: NAi Publishers.

Hyötyläinen R. (2000) Development mechanisms of strategic enterprise networks: Learning and innovation in networks, Espoo: Technical Research Centre of Finland.

Kogut B. (2000) The network as knowledge: Generative rules and the emergence of structure. Strategic Management Journal, vol. 21, no 3, pp. 405-425.

Kogut B., Zander U. (1992) Knowledge of the Firm, Combinative Capabilities, and the Replication of Technology. Organization Science, vol. 3, no 3, pp. 383-397.

Latora V., Marchiori M. (2004) The Architecture of Complex Systems, Santa Fe: Santa Fe Institute. Available at: http:// www.w3.org/People/Massimo/papers/2002/architecture_book_02.pdf, accessed 15.09.2015.

Leonard-Barton D. (1992) Core capabilities and core rigidities: A paradox in managing new product development. Strategic Management Journal, vol. 13 (special issue), pp. 111-125.

Leoncini R., Maggioni M.A., Montresor S. (1996) Intersectoral innovation flows and national technological systems: Network analysis for comparing Italy and Germany. Research Policy, vol. 25, no 3, pp. 415-430.

Lundvall B.-A. (ed.) (1992) National Systems of Innovation: Towards a Theory of Innovation and Interactive Learning, London: Pinter.

Lundvall B.-Å., Johnson B., Andersen E.S., Dalu B. (2002) National systems of production, innovation and competence building. Research Policy, vol. 31, no 2, pp. 213-231. 
Malerba F. (2004) Sectoral Systems of Innovation: Concepts, Issues and Analyses of Six Major Sectors in Europe, Cambridge, UK: Cambridge University Press.

Malerba F., Vonortas N., Cassi L., Corrocher N., Wagner C. (2007) Networks of Innovation in Information Society: Development and Deployment in Europe, Luxembourg: Office for Official Publications of the European Communities

Marshall A. (1961) Principles of Economics (9th ed.), London, New York: Macmillan for the Royal Economic Society.

Metcalfe S. (1995) The Economic Foundations of Technology Policy: Equilibrium and Evolutionary Perspectives. Handbook of the Economics of Innovation and Technological Change (ed. P. Stoneman), Oxford, UK; Cambridge, MA: Blackwell, pp. 409-512.

Mowshowitz A. (1968) Entropy and the complexity of graphs: I. An index of the relative complexity of a graph. The Bulletin of Mathematical Biophysics, vol. 30, no 1, pp. 175-204.

Nelson R.R., Winter S.G. (1982) An evolutionary theory of economic change, Cambridge, MA: Belknap Press of Harvard University Press.

Nishikawa T., Adilson E. Motter A.E., Ying-Cheng Lai Y.-C., Hoppensteadt F.C. (2003) Heterogeneity in oscillator networks: Are smaller worlds easier to synchronize? Physical Review Letters, vol. 91, no 1 (online publication). Available at: https://www.researchgate.net/publication/10622587_Heterogeneity_in_Oscillator_Networks_Are_ Smaller_Worlds Easier to Synchronize, accessed 15.10.2015.

Nooteboom B. (1992) Towards a dynamic theory of transactions, Tilburg: Tilburg University.

Nooteboom B. (2000) Learning by Interaction: Absorptive Capacity, Cognitive Distance and Governance. Journal of Management and Governance, vol. 4, no 1-2, pp. 69-92.

Nooteboom B. (2004) Inter-Firm Collaboration, Learning and Networks: An Integrated Approach, London; New York: Routledge.

Nooteboom B. (2005) Innovation, Learning and Cluster Dynamics, Tilburg: Tilburg University, Center for Economic Research.

Nooteboom B., Stam E. (2008) Micro-Foundations for Innovation Policy, Amsterdam: Amsterdam University Press.

OECD (1992) Technology and the economy: The key relationships, Paris: OECD.

Peterson J. (2003) Policy Networks (IHS Political Science Series: 2003, no 90), Vienna: Institute for Advanced Studies.

Pietrobelli C., Rabellotti R. (2009) Innovation Systems and Global Value Chains, Bologna: Universita di Bologna.

Piore M., Sabel C. (1986) The Second Industrial Divide: Possibilities for Prosperity (reprint edition), New York: Basic Books.

Powell W.W., Grodal S. (2005) Networks of Innovators. The Oxford Handbook of Innovation (eds. J. Fagerberg, D.C. Mowery, R.R. Nelson), Oxford; New York: Oxford University Press, pp. 56-85.

Powell W.W., Koput K.W., Smith-Doerr L. (1996) Interorganizational Collaboration and the Locus of Innovation: Networks of Learning in Biotechnology. Administrative Science Quarterly, vol. 41, no 1, pp. 116-145.

Prigogine I. (1976) Order Through Fluctuation: Self-Organization and Social System. Evolution and Consciousness: Human Systems in Transition (ed. E. Jantsch), Reading, MA: Addison-Wesley, pp. 93-130.

Prigogine I., Stengers I. (1984) Order out of chaos: Man's new dialogue with nature, Toronto; New York: Bantam Books.

Protogerou A., Caloghirou Y., Siokas E. (2010) Policy-driven EU Research Networks: Impact on the Greek SeT System, Copenhagen; Aalborg: Copenhagen Business School; Aalborg University.

Richardson J. (2000) Government, Interest Groups and Policy Change. Political Studies, vol. 48, no 5, pp. $1006-1025$.

Roediger-Schluga T., Barber M.J. (2006) The structure of R\&D collaboration networks in the European Framework Programmes, Maastricht: UNU-MERIT.

Ruef M. (2002) Strong ties, weak ties and islands: Structural and cultural predictors of organizational innovation. Industrial and Corporate Change, vol. 11, no 3, pp. 427-449.

Rycroft R.W. (2007) Does cooperation absorb complexity? Innovation networks and the speed and spread of complex technological innovation. Technological Forecasting and Social Change, vol. 74, no 5, pp. 565-578.

Saviotti P.P. (1988) Information, variety and entropy in technoeconomic development. Research Policy, vol. 17, no 2, pp. $89-103$

Schilling M.A., Phelps C.C. (2007) Interfirm Collaboration Networks: The Impact of Large-Scale Network Structure on Firm Innovation. Management Science, vol. 53, no 7, pp. 1113-1126.

Shannon C.E. (1948) A Mathematical Theory of Communication. Bell System Technical Journal, vol. 27, no 3, pp. 379-423. DOI: 10.1002/j.1538-7305.1948.tb01338.x.

Singh J. (2005) Collaborative Networks as Determinants of Knowledge Diffusion Patterns. Management Science, vol. 51 , no 5 , pp. $756-770$.

Soete L., Arundel A. (1993) An integrated approach to European innovation and technology diffusion policy: A Maastricht memorandum, Brussels; Luxembourg: Commission of the European Communities.

Soh P.-H., Roberts E.B. (2003) Networks of innovators: A longitudinal perspective. Research Policy, vol. 32, no 9, pp. $1569-1588$.

Sole R.V., Valverde S. (2004) Information theory of complex networks: On evolution and architectural constraints. Complex Networks (eds. E. Ben-Naim, H. Frauenfelder, Z. Toroczkai), Heidelberg: Springer-Verlag, pp. 189-210.

Storper M. (1997) The Regional World: Territorial Development in a Global Economy, New York: Guilford Press.

Sturgeon T., Biesebroeck J.V., Gereffi G. (2008) Value chains, networks and clusters: Reframing the global automotive industry. Journal of Economic Geography, vol. 8, no 3, pp. 297-321.

Tatikonda M.V., Rosenthal S.R. (2000) Technology novelty, project complexity, and product development project execution success:A deeper look at task uncertainty in product innovation. IEEE Transactions on Engineering Management, vol. 47, no 1, pp. 74-87.

Ter Wal A.L.J., Boschma R. (2011) Co-evolution of Firms, Industries and Networks in Space. Regional Studies, vol. 45, no 7, pp. 919-933.

Tsai W. (2002) Social Structure of "Coopetition" within a Multiunit Organization: Coordination, Competition, and Intraorganizational Knowledge Sharing. Organization Science, vol. 13, no 2, pp. 179-190.

Tsai W., Ghoshal S. (1998) Social Capital and Value Creation: The Role of Intrafirm Networks. Academy of Management Journal, vol. 41, no 4, pp. 464-476.

Uzzi B., Spiro J. (2005) Collaboration and Creativity: The Small World Problem. American Journal of Sociology, vol. 111, no 2, pp. 447-504.

Varblane U., Dyker D., Tamm D., von Tunzelmann N. (2007) Can the National Innovation Systems of the New EU Member States Be Improved? Post-Communist Economies, vol. 19, no 4, pp. 399-416.

von Hippel E. (1988) The Sources of Innovation, New York; Oxford: Oxford University Press.

Wang B., Tang H., Guo C., Xiu Z. (2006) Entropy Optimization of Scale-Free Networks Robustness to Random Failures. Physica A: Statistical Mechanics and Its Applications, vol. 363, no 2, pp. 591-596.

Weber M., Paier M., Heller-Schuh B., Scherngell T., Barber M. (2009) Evaluating R\&D collaboration networks Lessons from a comprehensive interdisciplinary modelling approach (Project number NEST-2006-028875 Network Models, Governance and R\&D Collaboration Networks (NEMO), Deliverable D5.1), Vienna: AIT Austrian Institute of Technology GmbH.

Wu J., Tan Y.-J., Deng H.-Z., Zhu D.-Z. (2010 A new measure of heterogeneity of complex networks based on degree sequence. Unifying Themes in Complex Systems (eds. A. Minai, D. Braha, Y. Bar-Yam), Berlin; Heidelberg: Springer, pp. 66-73. 